\title{
The role of physician oversight on advanced practice nurses' professional autonomy and empowerment
}

\section{Authors: Polly A. Petersen \& Sandra M. Way}

This is the peer reviewed version of the following article: see full citation below, which has been published in final form at https://dx.doi.org/10.1002/2327-6924.12444. This article may be used for non-commercial purposes in accordance with Wiley Terms and Conditions for Self-Archiving.

Petersen, Polly A, and Sandra M Way. "The role of physician oversight on advanced practice nurses' professional autonomy and empowerment." Journal of the American Association of Nurse Practitioners 29 (May 2017): 272-281. DOI: 10.1002/2327-6924.12444.

Made available through Montana State University's $\underline{\text { ScholarWorks }}$ 


\title{
The role of physician oversight on advanced practice nurses' professional autonomy and empowerment
}

\author{
Polly A. Petersen, PhD, RN (Assistant Professor) ${ }^{1}$ \& Sandra M. Way, PhD (Associate Professor) ${ }^{2}$ \\ ${ }^{1}$ College of Nursing, Montana State University, Bozeman, Montana \\ ${ }^{2}$ Department of Sociology, New Mexico State University, Las Cruces, New Mexico
}

\begin{abstract}
Background and purpose: Little is known about the effects of physician oversight on advanced practice registered nurses (APRNs). Examination of these relationships provides insight into the strength of independent practice. The purpose of this study was to examine whether APRNs' perceptions of autonomy and empowerment varied according to type of physician oversight, whether facilitative or restrictive.

Data sources: A cross-sectional survey design was used to examine whether APRNs' perceptions of autonomy and empowerment varied according to physician oversight, geographical location, and practice setting. Five hundred questionnaires were mailed in March 2013 with 274 returned. Participants were asked about autonomy, empowerment, demographics, physician oversight, geographical location, and practice setting.

Conclusions: Among surveyed respondents, physician oversight was related to increased empowerment, regardless of whether the oversight was defined in facilitative or restrictive terms; both had similar positive effects on empowerment. Implications for practice: If APRNs are to be part of the solution to the growing problem of healthcare access, it is important to study factors that contribute to their success. We speculate that increasing opportunities for collaboration and interaction with physicians, and possibly other healthcare professionals, could facilitate APRN empowerment, optimizing their contribution.
\end{abstract}

\section{Introduction}

One of the biggest challenges for health care worldwide is the chronic shortage of primary care providers (PCPs). In many places, including Canada, Europe, Australia, and New Zealand, the number of retiring PCPs exceeds the number of new physicians (McInnes, Peters, Bonney, \& Halcomb, 2015). These shortages are likely to worsen in light of aging populations with multiple chronic health issues and increasing patient demands. This is particularly relevant in the United States where recent implementation of the Affordable Care Act has led to a higher demand for health care at the same time the supply of primary care physicians continues to decline.

One solution for this shortage of providers has been the development and increased utilization of nonphysician PCPs such as advanced practice registered nurses (APRNs; Maier, 2015; Pulcini, Jelic, Gul, \& Yuen, 2010; Sheer \&
Wong, 2008). Evidence demonstrates that APRNs who practice as independent care providers are producing similar patient outcomes to primary care physicians (Fund \& Swanson-Hill, 2014; Horrocks, Anderson, \& Salisbury, 2002; Laurant et al., 2009; Martinez-Gonzalez, Tandjung, Djalali, \& Roseman, 2015; Newhouse et al., 2011). Consequently, researchers and policymakers alike have been advocating for the expanded practice and autonomy of APRNs to assume an enhanced role in health care. While there is significant potential for APRNs to help lessen the need for PCPs, research shows a variety of barriers exist that limit scope of practice and hinder implementation of APRNs as independent PCPs. For example, in many countries, APRN practice lacks clarity in roles and an absence of standardization (Gardner, Chang, Duffield, \& Doubrovsky, 2012). Other barriers include regulations, hospital requirements limiting independent practice, physician dominance, and 
opposition to autonomy and expansion of the APRN role from organized medical groups (Brooten, Youngblut, Hannan, \& Guido-Sanz, 2012; Donelan, DesRoches, Dittus, \& Buerhaus, 2013; Gutchell, Idzik, \& Lazear, 2014; Weiland, 2008).

In order to function in the role of PCP, it is important that APRNs perceive that they are autonomous and feel empowered or confident in their role, responsibilities, and competencies in caring for patients. Even though independent practice of APRNs has significantly evolved in recent years, factors that influence nurse autonomy and empowerment remain poorly understood. This research focused on one potential barrier, physician oversight, to determine if there was an association with professional autonomy and empowerment among a sample of APRNs in Montana, a state located in the northwestern United States.

\section{Background}

Many countries have adopted legislation addressing APRN scope of practice that allows for independent practice (Pulcini et al., 2010). In the United States, more than 13 states have adopted the National Council of State Boards of Nursing (2016) APRN consensus model that promotes standardization of licensure, accreditation, certification, and education of all advanced practice nurses. This includes Montana, a predominantly rural state with 47 critical access hospitals (CAHs; Department of Public Health and Human Services, 2011) and the location of this study. As is the case in many states that allow independent practice, in Montana most APRNs practice under some form of regulatory physician oversight, because insurance reimbursement and healthcare facilities, particularly CAHs, often require physician cosignature and/or chart review for APRNs.

Autonomy has been used simultaneously to define both the legal authority and the practical ability to provide primary care using independent judgment and selfgovernance (Weiland, 2008). Brown and Draye (2003) noted the importance of autonomy in practice for APRNs, allowing them to develop a relationship-focused model of care that was felt to enhance the health of patients. Health professionals and scholars have argued that autonomy for APRNs is essential for professional recognition and status (Dempster, 1990; Wade, 1999). In addition, autonomy among APRNs has been linked to other important factors such as patient outcomes and job satisfaction (Newhouse et al., 2011; Pasarón, 2012).

Empowerment is also important for independent practice. Chandler (1991) defines empowerment as "enabling individuals to feel effective so that they can successfully execute their jobs" (p. 66). Empowerment comes from the ability to get things done by successfully accessing lines of information, support, resources, and opportunities to learn and grow (Kanter, 1993). Work environments with social structures that provide for these sources of support and power lend to the development of strong interpersonal relationships (Laschinger, Almost, \& TuerHodes, 2003). APRNs that are allowed independent practice, including through regulatory agencies, are primed to seek these environments to support their own empowerment, establish working relationships with fellow healthcare providers, as well as successfully perform their role as PCPs.

One of the primary factors shaping APRNs as PCPs is the role of the collaborating physician within the healthcare team. Collaboration that comes from primary care teams, which include supervising physicians, can be beneficial for primary care APRNs, resulting in support and availability for consult, particularly of more complex patients (Mitchell et al., 2013). Research suggests good working relationships, collaboration with physicians, and trust in the team contribute to both autonomy and informal empowerment (Almost \& Laschinger, 2002; Maylone, Ranieri, Quinn-Griffin, McNulty, \& Fitzpatrick, 2011). However, physicians who are too authoritarian or bureaucratic in their interactions may stifle autonomy or disempower APRNs, impeding instead of bolstering independent practice. One recent study found that on average, APRNs perceived physician oversight to have a negative impact on the safety and quality of care delivered by APRNs (Lowery, Scott, \& Swanson, 2016).

In many cases, state and institutional policies dictate the amount of oversight physicians have over APRNs. Restrictive practice and discrepancies of APRN roles can create a barrier to effective collaboration that may ultimately affect health care of patients (Health Resources and Services Administration [HRSA], 2014). Achieving a better understanding of how physician oversight is related to APRN autonomy and empowerment is particularly relevant as we look toward APRNs as one solution to increasing demands for health care.

Two additional factors that may contribute to the autonomy and empowerment of APRNs include the geographical location, whether rural or urban, and setting of practice, whether a clinic/outpatient setting or a hospital/long-term care facility. APRNs practicing in a rural setting often acknowledge a higher level of autonomy as well as a more interactive relationship with physicians (Petersen, Keller, Way, \& Borges, 2015). This may be because of the smaller size of the setting and fewer members of the healthcare team that results in less hierarchical organizational structures (Penz \& Stewart, 2008). On the other hand, providers in rural settings tend to have less access to empowering resources and support, despite 
enhanced technologies, federal funding programs, and opportunities for larger system support (Ricketts, 2000).

\section{Objectives/aim}

The aim of this study was to examine whether APRNs' perceptions of autonomy and empowerment varied according to predictor variables of physician oversight, geographical location, and practice setting in a predominantly rural state in the United States with regulatory policies that allow independent practice. Understanding how these variables relate to characteristics of autonomy and empowerment provides a clearer picture of potential enhanced utilization of APRNs as well as their professional stature. We predicted that APRNs working in rural areas, clinic settings, and without physician oversight would perceive higher levels of autonomy. It was unclear, however, whether APRNs working in such settings would feel more or less empowered. While more independent work environments often found in such settings may facilitate APRN empowerment, it is also possible that the relative lack of resources and support in rural areas and clinic settings may undermine APRN empowerment. Similarly, variation in the facilitative versus restrictive nature of physician oversight complicates its association with APRN's empowerment. While a recent study examining the link between physician oversight and APRN empowerment found a positive association between the two, potential differences between types of physician oversight were not examined (Petersen et al., 2015). Physician oversight might take the form of chart review, order or prescription cosignature, transfer of care for hospitalization, or other actions that depend on physicians for patient care processes. In order to explore the complexity of physician oversight, we embedded an open-ended question in the survey to help us discover the different types of physician oversight as defined by the respondents. Using qualitative coding, we discovered several themes that we clustered into two subsequent types of physician oversight categories: facilitative and restrictive. We expected that when compared to APRNs without physician oversight, APRNs reporting facilitative oversight would feel more empowered and those reporting restrictive oversight would feel less empowered.

\section{Methods \\ Design}

The study utilized a cross-sectional descriptive survey that also included an embedded open-ended question to elicit information related to the definition of physician oversight. The embedded mixed methods design is effective when requiring a qualitative answer to a research question within a larger quantitative study (Creswell \& Plano Clark, 2007). Quantitatively, the survey collected data from APRNs regarding autonomy and empowerment in their professional workplace setting and location. Five hundred names were randomly selected by the researchers from a list of all licensed APRNs in the state provided by the Montana Board of Nursing. Those participants selected were assigned a number to maintain anonymity.

\section{Setting/participants}

The sample included certified nurse specialists (CNSs), certified nurse practitioners (CNPs), certified registered nurse anesthetists (CRNAs), and certified nurse midwives (CNMs). A total of 500 surveys were distributed via the U.S. postal service during March 2013. A stamped envelope was provided with each survey and postcard reminders were sent 2 weeks prior to the end of the data collection. A total of 274 returned surveys (55\%) were utilized in the analysis. The study was conducted in Montana, a rural northwestern state in the United States, which has a total population of 1,000,000 and only three cities with populations greater than 50,000. In 2015, state legislation was passed to align the regulations for independent practice and the APRN Consensus Model. Although Montana allows for independent practice, most APRNs continue to practice under hospital policies or contractual obligations that require some form of physician oversight such as cosignature or chart review.

\section{Data collection}

The Dempster Practice Behavior Scale (DPBS) was used to measure the outcome variable autonomy. The DPBS is a 30-item instrument developed with a Likert-type format and a 5-point scaling that focuses on overt and covert behaviors, actions, and conduct related to the extent of an individual's autonomy in a practice setting (Dempster, 1990). Construct validity of this tool was established through a multitrait-multimethod matrix (Dempster, 1990). Reliability analysis from previous studies indicated a Cronbach's alpha (standardized item alpha) for the 30-item instrument of .95 with an overall interitem correlation mean of .39. Current study reliability analysis indicates similar results; Cronbach's $\alpha$ of .92 with a mean of .31 .

The Conditions of Work Effectiveness Questionnaire II (CWEQ-II) was used to measure the outcome variable of empowerment. The revised CWEQ-II, developed by Laschinger, Finegan, Shamian, and Wilk (2001), consists of 19 items that measure the six subscales of structural empowerment (opportunity, information, support, resources, 
formal power, and informal power). These subscales help define the relationship the APRN has within the healthcare team as well as in the practice setting. Based on results of a confirmatory factor analysis that validated the factor structure of this instrument conducted by Laschinger et al. (2001), a total empowerment score is created by summing the subscales of the CWEQ-II. Cronbach's $\alpha$ reliabilities in previous studies range from .79 to .82 (Laschinger et al., $2001)$. Reliability analysis for the current study indicates a Cronbach's $\alpha$ of .915 with an overall interitem correlation mean of .334 .

Type of physician oversight was operationalized using definitions provided by the participants. Respondents were first asked whether or not they practiced under physician oversight. If they responded yes, they were asked to define oversight in their own words. Using a qualitative embedded design approach, the need for the participant to answer how they defined physician oversight was necessary to understand this independent variable. Definitions given were then examined and coded for recurring themes. Despite federal and state policies as well as contractual obligations that require some form of physician oversight in practice settings for many APRNs, the reported themes were varied and subjective. Seven themes emerged: collaborative, mentor, resource, consulting, contractual, or regulatory (which includes such definitions as chart review/cosignature, terms of employment, and accreditation requirements of the facility), cosignature for prescription $(\mathrm{Rx})$ or diagnostic $(\mathrm{Dx})$ tests and specialty practice. For the purpose of statistical analysis and consistent with our argument that some types of physician oversight might enable APRN autonomy and empowerment while others may inhibit it, these themes were then clustered and used to categorize oversight as either facilitative or restrictive. Respondents who used terms that would indicate support such as collaborative, mentor, resource, and consulting were coded facilitative, while respondents who used terms that suggest limits to independent practice such as contractual, regulatory, $\mathrm{Rx} / \mathrm{Dx}$, and specialty practice were coded restrictive. Definitions that included both facilitative and restrictive themes were included in the facilitative category in order to isolate possible negative effects of restrictive physician oversight. Unclear definitions or responses that did not relate to practice setting were included in a third category along with participants who responded yes to physician oversight, but offered no definition. The categorization of each respondent's definition was substantiated by two outside reviewers.

\section{Ethical considerations}

Ethics approval was obtained from a university institutional review board. Each participant was given an identification number to eliminate potential for personal identification. Return of the survey items indicated consent for participation.

\section{Data analysis}

In the initial analysis, we conducted descriptive statistics and explored possible confounders by examining demographic characteristics in relation to both the categorical predictors and continuous outcome variables. Chi-square analysis was conducted to determine if there were any significant differences between groups. For variables with multiple categories, follow-up Z-tests between column proportions with Bonferroni corrections were utilized to determine which specific categories were significantly different from each other. For autonomy and empowerment scores, analysis of variance (ANOVA) with Bonferroni corrected post hoc tests were used to test for significant differences. Demographic information collected included

- level of education,

- years of advanced practice,

- area of practice, practice setting, geographic location,

- and type of physician oversight with definition, age, gender, and ethnicity

Mean differences in perceived autonomy and empowerment were then examined across the three predictor variables, physician oversight, practice setting, and geographical location, utilizing independent $t$-tests with Sidak $p$-value adjustments.

Finally, we conducted multivariate linear regression to examine whether types of physician oversight were differentially related to autonomy and empowerment. Dummy variables were constructed to capture different types of physician oversight. Those respondents indicating they practiced under one of the facilitative types of physician oversight were coded 1 for the variable facilitative while all other respondents were coded 0 . Similarly, those respondents indicating they practiced under one of the restrictive types of physician oversight were coded 1 for the variable restrictive while all other respondents were coded 0 . For respondents who indicated they practice under physician oversight but did not provide information regarding the type of oversight or who provided definitions that could not be classified into either facilitative or restrictive, a third dummy variable was created (oversight; no definition $=1$, else $=0$ ) and included in the model as a control. Consequently, the comparison for all three physician oversight dummy variables is the group of APRNs with no physician oversight. In addition to the two primary predictors of facilitative and restrictive physician oversight, geographical location 
(rural $=0$, urban $=1$ ) and practice setting (clinic $=$ 0 , hospital =1) were included as covariates. Any potential demographic confounders found in the initial analyses were also included. Two multivariate linear regression analyses were conducted, one for autonomy and one for empowerment.

\section{Results}

\section{Participants}

Returned surveys $(n=274)$ revealed that $81.3 \%$ of the participants held a Master's in Science of Nursing (MSN) and $79.3 \%$ practiced as a CNP. CNMs comprised only $4.4 \%$, CNSs only $4.4 \%$, and CRNAs $11.9 \%$. Of participating APRNs, $60.9 \%$ practiced in rural areas that were defined as less than 50,000 residents, $76.7 \%$ worked in a clinic/outpatient setting. Slightly more than half $(52.8 \%)$ of APRNs who participated in this study reported physician oversight. The percentage of APRNs who responded with each of the initial seven themes were collaborative $20.3 \%$, mentor $6.3 \%$, resource $3.5 \%$, consulting $25.2 \%$, contractual or regulatory $50.3 \%, \mathrm{Rx} / \mathrm{Dx} 2.1 \%$, and specialty practice $9.8 \%$. This includes multiple definitions from some respondents. For the oversight dummy variables included in the statistical analysis, $57.0 \%$ were coded as facilitative, $34.7 \%$ were restrictive, and $8.3 \%$ had an unclear or no definition.

\section{Descriptive data}

Table 1 presents demographic percentages within each category of the predictor variables: geographical location, physician oversight, and practice setting. Several of the respondent characteristics were related to one or more predictor variables. All of the following comparisons were statistically significant at $p<.05$. Urban APRNs were more likely to be female $(88.7 \%)$ and to be practicing as CNPs $(82.7 \%)$, compared to rural APRNs $(78.3 \%$ and $77.0 \%$, respectively). APRNs with and without physician oversight differed in their level of education, area of practice, and years in practice. APRNs with physician oversight had a higher percentage practicing as a CNP $(90.1 \%)$ compared to those without physician oversight $(66.7 \%)$ and APRNs without physician oversight had a higher percentage practicing as CNSs $(7.1 \%$ compared to $2.1 \%$ ) of those with physician oversight or CRNAs $(22.2 \%$ compared to $2.8 \%$ with physician oversight). APRNs with physician oversight have less experience than their counterparts with no oversight, with a higher percentage practicing for less than 1 year $(9.6 \%$ vs. $3.2 \%)$ and a lower percentage practicing for more than 20 years (17.8\% vs. $29.1 \%$ ). More of the clinic APRNs were female $(88.5 \%)$ compared to those in hospitals $(61.0 \%)$. Only $50.8 \%$ of hospital APRNs practice as CNPs. Hospital APRNs are more likely to practice as CRNAs $(36.1 \%)$ or CNMs $(9.8 \%)$. This compares to $5.0 \%$ CRNAs and $3.0 \%$ CNMs practicing in the clinic setting.

Only one demographic variable was found to be significantly related to either of the outcome variables. There was a significant effect of APRNs' area of practice on empowerment $(F=3.058, p=.029)$; Bonferroni post hoc tests indicated statistically significant empowerment score differences $(p=.026)$ between CRNAs $(M=22.08, S E=$ $0.63)$ and CNSs $(M=18.26, S E=1.54)$. Although the other two areas of practice, CNPs $(M=20.82, S E=0.85)$ and CNMs $(M=21.90, S E=1.32)$, were also several points lower than CRNAs, these differences were not significant.

Table 2 provides the percentages for each of the predictor variables within each of the other predictor variables. Similar to Table 1, chi-square analysis was conducted to determine if there were any significant differences between the groups. No significant relationship was found between physician oversight and practice setting. Physician oversight was related to geographical location $\left(\chi^{2}=11.87, p<\right.$ $.001)$, with physician oversight more common in urban locations $(66.3 \%)$ than in rural locations $(45.0 \%)$.

\section{Autonomy and empowerment scores}

The mean autonomy score for APRNs was 124.98, $S D=$ 17.61 of a possible 150; the mean empowerment score was $20.91, S D=3.96$ of a possible 30 , indicating fairly autonomous and empowered APRN participants. Tables 3 and 4 provide $t$-test analyses of mean autonomy and empowerment scores by physician oversight, geographical location, and practice setting. Mean differences in autonomy scores were in the expected direction, but were not significant for any of the predictor variables. Mean differences in empowerment scores were statistically significant for physician oversight $(t=3.38 ; p<.01)$. APRNs that practiced without physician oversight $(n=126$, $M=20.07$ ) were less empowered than those who practiced with physician oversight ( $n=141, M=21.68$ ).

The multivariate regression analyses are reported in Tables 5 and 6 . Because area of practice was found to be related to both predictor variables and the outcome variable empowerment (see Table 1), it was included in the analysis as a control variable. The autonomy analysis found no significant associations between APRN autonomy and facilitative or restrictive physician oversight, after adjusting for the other characteristics of area of practice, practice setting, and geographical location. In addition, the $F$-ratio for the overall model for autonomy was not significant $(F=$ 1.88, $p=.064)$. The overall model for empowerment, however, was significant $(F=3.85, p<.001)$ with 


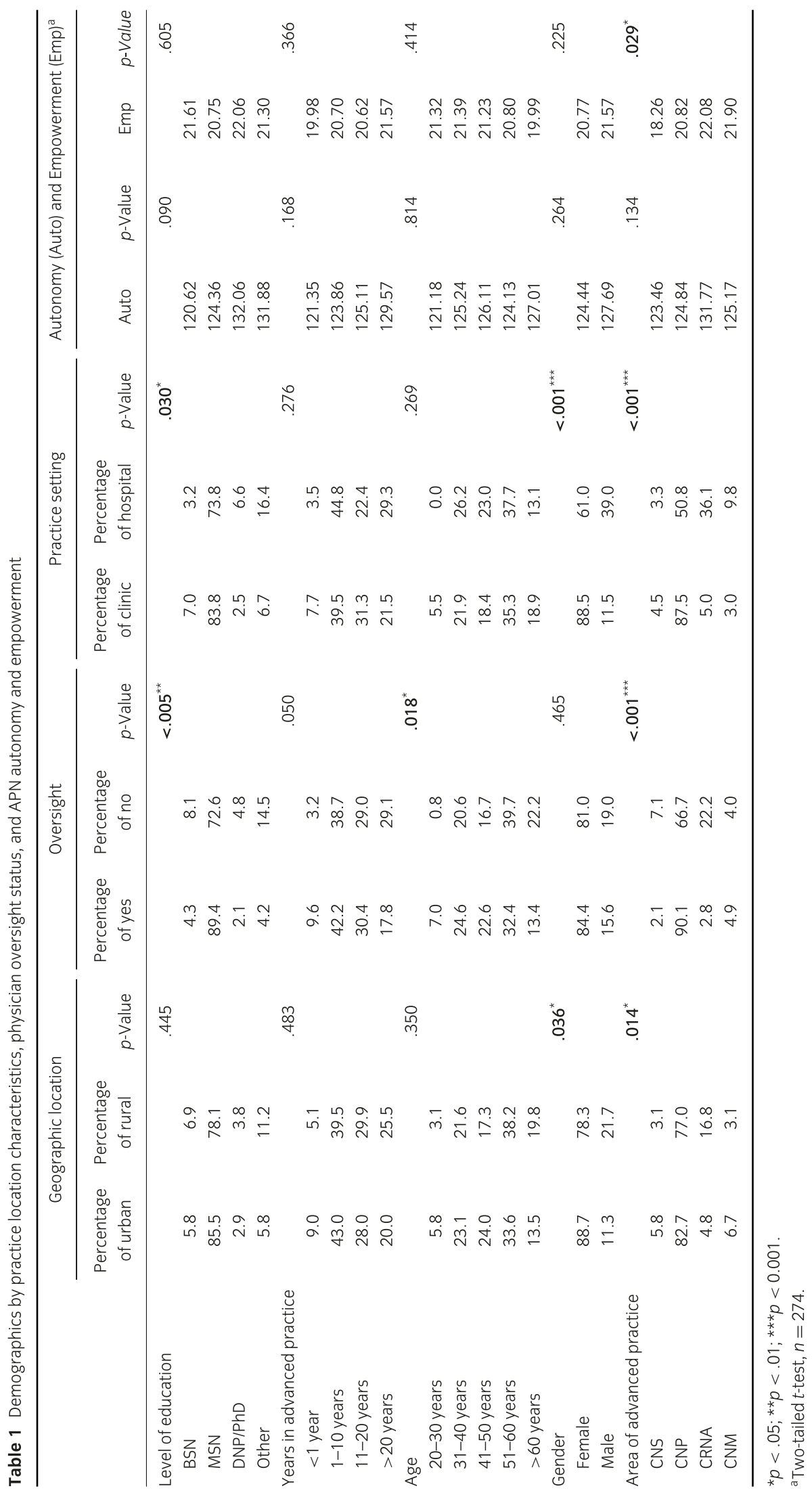


Table 2 Associations between predictor variables

\begin{tabular}{|c|c|c|c|c|c|c|c|c|c|}
\hline & $\begin{array}{c}\text { Percentage } \\
\text { of urban }\end{array}$ & $\begin{array}{c}\text { Percentage } \\
\text { of rural }\end{array}$ & $p$-Value & $\begin{array}{l}\text { Percentage } \\
\text { of oversight }\end{array}$ & $\begin{array}{c}\text { Percentage } \\
\text { of } \\
\text { nonoversight }\end{array}$ & $p$-Value & $\begin{array}{c}\text { Percentage } \\
\text { of clinic }\end{array}$ & $\begin{array}{l}\text { Percentage } \\
\text { of hospital }\end{array}$ & $p$-Value \\
\hline Setting of practice & & & .683 & & & .614 & & & \\
\hline Clinic & 75.0 & 77.2 & & 77.9 & 75.2 & & & & \\
\hline Hospital & 25.0 & 22.8 & & 22.1 & 24.8 & & & & \\
\hline Physician oversight & & & $<.001^{\star \star \star \star}$ & & & & & & .614 \\
\hline Oversight & 66.3 & 45.0 & & & & & 54.5 & 50.8 & \\
\hline No oversight & 33.7 & 55.0 & & & & & 45.5 & 49.2 & \\
\hline Geographical location & & & & & & $<.001^{\star \star}$ & & & .683 \\
\hline Urban & & & & 48.9 & 28.5 & & 38.1 & 41.0 & \\
\hline Rural & & & & 51.1 & 71.5 & & 61.9 & 59.0 & \\
\hline
\end{tabular}

${ }^{\star} p<.05 ;{ }^{* \star} p<.01 ; * \star * p<.001$, chi-square.

Table 3 Autonomy scores

\begin{tabular}{lccc}
\hline & Mean score & SD & p-Value \\
\hline $\begin{array}{l}\text { Physician oversight } \\
\text { Oversight }\end{array}$ & 124.49 & 12.81 & \\
No oversight & 127.78 & 14.43 & \\
Mean difference & -2.88 & & .151 \\
Geographical location & & & \\
Rural & 127.02 & 16.72 & .219 \\
Urban & 123.51 & 14.43 & \\
Mean difference & 3.51 & & .997 \\
Practice setting & & & \\
Outpatient/clinic & 126.09 & 13.71 & \\
Hospital/long term & 125.74 & 15.03 & \\
Mean difference & 0.35 & & \\
\hline
\end{tabular}

${ }^{\star} p<.05,{ }^{* \star} p<.01,{ }^{* \star *} p<.001$; two-tailed $t$-test, Sidak corrected $p$ values.

$11 \%\left(R^{2}=.11\right)$ of the variance in empowerment scores explained by the three predictor variables and the controls. APRNs practicing as CNSs $(\beta=-4.22, p<.01)$ and CNPs $(\beta=-1.97, p<.05)$ felt significantly less empowered than their CRNA counterparts. Adjusting for the other predictor variables, APRNs practicing with any type of physician oversight whether facilitative $(\beta=1.66, p<.01)$ or restrictive $(\beta=1.81, p<.01)$, reported feeling more empowered than those who practiced without physician oversight. There was no significant difference in empowerment between APRNs who defined their experience of physician oversight in facilitative and those who defined their experience of physician oversight in restrictive terms $(t=0.410, p=.68)$.

\section{Discussion}

The most interesting and robust finding in our study was the link between physician oversight and APRN empowerment. Our initial analysis found that on average, APRNs practicing with physician oversight felt more empowered than their colleagues who did not.
Table 4 Empowerment scores

\begin{tabular}{|c|c|c|c|}
\hline & Mean score & $S D$ & $p$-Value \\
\hline \multicolumn{4}{|l|}{ Physician oversight } \\
\hline Oversight & 21.68 & 3.69 & \\
\hline No oversight & 20.07 & 4.12 & \\
\hline Mean difference & 1.81 & & $.003^{\star \star}$ \\
\hline \multicolumn{4}{|l|}{ Geographical location } \\
\hline Rural & 20.70 & 3.88 & \\
\hline Urban & 21.40 & 4.01 & \\
\hline Mean difference & -0.70 & & .405 \\
\hline \multicolumn{4}{|l|}{ Practice setting } \\
\hline Outpatient/clinic & 20.67 & 4.06 & \\
\hline Hospital/long term & 21.79 & 3.52 & \\
\hline Mean difference & -1.12 & & .151 \\
\hline
\end{tabular}

Table 5 Regression predicting autonomy

\begin{tabular}{lccccc}
\hline & $\beta$ & SE & $\beta$ & $p$-Value & $R^{2}$ \\
\hline Constant & 133.73 & 2.93 & & $<.001$ & .06 \\
Area of APRN $^{\mathrm{a}}$ & & & & & \\
$\quad$ CNS & $-10.41^{*}$ & 5.23 & -.14 & .047 & \\
CNP & -5.82 & 3.13 & -.17 & .064 & \\
CNM & -4.88 & 4.86 & -.07 & .317 \\
Type of physician oversight & & & & & \\
$\quad$ Facilitative & -3.10 & 2.18 & -.10 & .157 \\
$\quad$ Restrictive & -0.09 & 2.50 & -.00 & .971 & \\
$\quad$ No definition & 2.39 & 4.25 & .04 & .575 & \\
Geographic location and setting & & & & & \\
$\quad$ Urban & -2.75 & 1.87 & -.10 & .142 & \\
$\quad$ Hospital & -2.05 & 2.30 & -.06 & .373 & \\
\hline
\end{tabular}

a Dummy coded in reference to CRNA.

${ }^{b}$ Dummy coded in reference to no oversight.

'Dummy coded in reference to rural and clinic/outpatient.

${ }^{*} p<.05, * * p<.01$. 
Table 6 Regression predicting empowerment

\begin{tabular}{|c|c|c|c|c|c|}
\hline & $\beta$ & SE & $\beta$ & $p$-Value & $R^{2}$ \\
\hline Constant & 21.30 & 0.80 & & $<.001$ & .11 \\
\hline \multicolumn{6}{|l|}{ Area of APRN ${ }^{a}$} \\
\hline CNS & $-4.22^{\star \star}$ & 1.42 & -.21 & .003 & \\
\hline CNP & $-1.97^{\star}$ & 0.85 & -.20 & .021 & \\
\hline CNM & -1.13 & 1.32 & -.06 & .392 & \\
\hline \multicolumn{6}{|c|}{ Type of physician oversight ${ }^{b}$} \\
\hline Facilitative & $1.66^{\star *}$ & 0.60 & .20 & .006 & \\
\hline Restrictive & $1.81^{* *}$ & 0.68 & .18 & .008 & \\
\hline No definition & $3.57^{\star *}$ & 1.16 & .19 & .002 & \\
\hline \multicolumn{6}{|c|}{ Geographic location and setting ${ }^{c}$} \\
\hline Urban & 0.77 & 0.51 & .10 & .130 & \\
\hline Hospital & 0.54 & 0.63 & .06 & .386 & \\
\hline
\end{tabular}

a Dummy coded in reference to CRNA.

${ }^{b}$ Dummy coded in reference to no oversight.

${ }^{\mathrm{c}}$ Dummy coded in reference to rural and clinic/outpatient.

${ }^{*} p<.05,{ }^{*} p<.01$

Suspecting that physician oversight was multifaceted, we predicted that physician oversight that was mandated and regulatory in nature might create barriers for APRN independent practice, reducing empowerment, while other types of oversight would facilitate collaboration, increasing APRN empowerment. However, the multivariate regression results found no difference between facilitative and restrictive oversight. When compared to scores of APRNs without physician oversight, both facilitative and restrictive types of oversight had significantly higher empowerment scores, controlling for geographical location, practice setting, and area of APRN practice. Counter to expectations, results suggested that physician oversight stemming from regulatory mandates, such as contractual language, support APRN empowerment in some way. There was no evidence that empowerment was related to geographic location (urban or rural) or practice setting (hospital or clinic/outpatient). It is worth noting, however, that the independent $t$-test results for physician oversight and geographical location approached significance $(p<.1)$, with fewer rural nurses reporting physician oversight. Given the relationship found between physician oversight and empowerment, this might point to the need for more physician/APRN interactions in rural areas.

Our investigation of APRN autonomy was less insightful. The mean scores for autonomy were consistent with our prediction that APRNs practicing in rural areas, clinic settings, and without physician oversight would feel more autonomous. Those scores were all higher than those for APRNs in urban areas, practicing in a hospital setting with physician oversight (Table 3). However, none of the statistical analysis were found to be significant.

\section{Limitations}

Although results indicated that all measured types of physician oversight were positively correlated with empowerment, because of the limitation of our measures and analysis, we caution against using these findings to support regulatory increases in physician oversight of APRNs. First, our categorization of facilitative and restrictive definitions is an initial attempt to differentiate various circumstances that APRNs identify as oversight. Unfortunately, because of the low number of APRNs that practice with certain types of oversight, it was not possible to examine differences in empowerment for more specific categories. While these initial categories do capture some of the structural differences that APRNs use to define their situation with physicians, they do not capture levels of oversight or important details at the interactional level. If physician oversight leads to higher empowerment for APRNs, we can only speculate on the mechanism through which this occurs. Literature that discusses collaborative healthcare teams suggests a partial explanation for our findings may reside in the benefits of working within a team. For example, working with any type of physician oversight potentially increases opportunities for teamwork and collaboration. This collaboration could improve patient care and outcomes as well as develop the relationship between team members. Many APRNs and physicians, who work side by side, recognize the relationship within the team as more synergistic than competitive (Bahouth, EspositoHerr, \& Babineau, 2007).

Because of the regulatory environment in Montana, most APRNs in this study would have been officially practicing under regulatory policies that required some form of physician oversight. Despite this, almost half of the APRNs in the study responded that they did not practice under physician oversight, suggesting that perceptions of oversight may be less dependent on official regulations and more on the relationship the APRN has with the supervising physician. One possibility is that the amount or level of interaction, regardless of how it was defined, led the APRNs in the study to perceive the relationship as oversight and it is that interaction, not formal or official oversight, that manifests in empowerment.

Additionally, there are limits to any correlational analysis. It is possible that the relationship between physician oversight and empowerment is spurious. For example, physician oversight may be more common in resourcerich environments and where there is a higher density of providers, including specialists who are available for collaboration. If this is the case, attempts to empower APRNs by simply requiring physician oversight would be ineffective. Instead, efforts would be better focused on increasing access to professional colleagues. This may be 
particularly important in rural areas, if rural APRNs have less physician oversight.

\section{Conclusion}

To achieve improved outcomes in a timely fashion, the future healthcare system will require that all PCPs connect to resources and support that can improve health (Brooten et al., 2012). This will require that all providers, including APRNs, practice at the optimum level of education and experience. If we continue to look toward APRNs as one of the main solutions to the growing problem of primary healthcare access, it is important to study the factors that contribute to their success to accomplish this care. Our study suggests that one promising topic for future research in this area is the relationship between APRNs and physicians.

This study found that APRNs who reported physician oversight also reported higher levels of empowerment, suggesting that overseeing physicians may be an important resource for APRNs. A more narrow interpretation of this result might suggest the need for maintaining and perhaps even strengthening current regulations that dictate some form of physician oversight. However, this interpretation may be overly simplistic. For one, the high percentage of respondents who indicated no physician oversight, despite practicing in a state where most APRNs officially practice under some form of regulatory oversight, suggests that policies that require actions such as cosignatures and chart reviews may not translate into meaningful or perhaps even perceivable interactions between APRNs and overseeing physicians. Identifying a relationship with a physician as oversight may simply have reflected the saliency of the relationship to the respondent. The fact that oversight described by respondents as restrictive was equally as empowering as the oversight that was described as facilitative supports this interpretation. In this case, policies that aim to more generally connect APRNs and physicians may be more beneficial for empowering nurses than ones that focus on limiting APRN authority. In addition, although this study only examined the APRN/physician relationship, potential benefits resulting from professional interactions may not be exclusive to physicians but extend to other professional colleagues as well. This would present even more options for enhancing APRN empowerment and patient outcomes.

While we have speculated on possible implications in order to implement relevant policy, it is important to better understand the mechanisms by which physician oversight is related to APRN empowerment. Additional research that focuses on the underlying factors behind why APRNs who report physician oversight feel more empowered is an im- portant next step. This will further contribute to the understanding of the APRN/physician relationship.

Finally, the fact that rural APRNs were less likely to practice with physician oversight deserves further investigation. If this is the case more generally, drilling down to understand how physician oversight impacts empowerment of APRNs may be particularly relevant to rural health care, where shortages of PCPs tend to be most acute. In some places, the implementation of healthcare teams, physicianled or otherwise, might be effective, but in rural areas that have fewer resources and personnel, alternatives may be needed.

\section{Acknowledgments}

Polly Petersen wrote the initial draft of this manuscript, developed the research project, collected the data, performed the initial analysis, and revised for final submission. Sandra Way made significant revisions of the initial draft of this manuscript, final submission revisions and performed the final data analysis with explanations.

\section{References}

Almost, J., \& Laschinger, H. K. S. (2002). Workplace empowerment, collaborative work relationships, and job strain in nurse practitioners Journal of American Academy of Nurse Practitioners, 14(9), 408-420.

Bahouth, M., Esposito-Herr, M. B., \& Babineau, T. J. (2007). The expanding role of the nurse practitioners in an academic medical center and its impact on graduate medical education. Journal of Surgical Education, 64(5), 282-288. doi:10.1016/j.jsurg.2007.08.002

Brooten, D., Youngblut, J. M., Hannan, J., \& Guido-Sanz, F. (2012). The impact of interprofessional collaboration on the effectiveness, significance, and future of advanced practice registered nurses. Nursing Clinics of North America, 47(2), 283-294, doi:10.1016/I,cnur.2012.005

Brown, M. A., \& Draye, M. A. (2003). Experiences of pioneer nurse practitioners in establishing advanced practice roles. Journal of Nursing Scholarship, 35(4), 391-397.

Chandler, G. E. (1991). Creating an environment to empower nurses. Nursing Management, 22(8), 20-23.

Creswell, J. W., \& Plano Clark, V. L. (2007). Choosing a mixed methods design. Designing and conducting mixed methods research (pp. 58-88). Thousand Oaks, CA: Sage Publications.

Dempster, J. S. (1990). Autonomy in practice: Conceptualization, construction, and psychometric evaluation of an empirical instrument. Dissertation Abstract International, 50, 3320A.

Department of Public Health and Human Services. (2011). Montana's rural health plan. Retrieved November 17, 2016, from http://www.mtpin.org

Donelan, K., DesRoches, C. M., Dittus, R. S., \& Buerhaus, P. (2013). Perspectives of physicians and nurse practitioners on primary care practice. New England Journal of Medicine, 368(20), 1898-1906. doi:10.1056/NEJMsa1212938

Fund, M. E., \& Swanson-Hill, A. (2014). Cost-effectiveness of nurse practitioner care. The Kansas Nurse, 89(1), 12-15.

Gardner, G., Chang, A. M., Duffield, C., \& Doubrovsky, A. (2012). Delineating the practice profile of advanced practice nursing: A cross-sectional survey using the modified strong model of advanced practice. Journal of Advanced Nursing, 69(9), 1931-1942. doi:10.1111/jan.12054

Gutchell, V., Idzik, S., \& Lazear, J. (2014). An evidence-based path to removing APRN practice barriers. The Journal for Nurse Practitioners, 10(4), 255-261. 
Health Resources and Services Administration (HRSA). (2014). Data warehouse Retrieved August 29, 2014, from http://hpsafind.hrsa.gov

Horrocks, S., Anderson, E., \& Salisbury, C. (2002). Systematic review of whether nurse practitioners working in primary care can provide equivalent care to doctors. BMJ, 324, 819-823.

Kanter, R. M. (1993). Men and women of the corporation. New York, NY: Basic Books.

Laschinger, H. K. S., Almost, J., \& Tuer-Hodes, D. (2003). Workplace empowerment and magnet hospital characteristics: Making the link. Journal of Nursing Administration, 33(7/8), 410-422.

Laschinger, H. K. S., Finegan, J., Shamian, J., \& Wilk, P. (2001). Impact of structural and psychological empowerment on job strain in nursing work settings: Expanding Kanter's model. Journal of Nursing Administration, 31(5), 260-272.

Laurant, M., Harmsen, M., Wollersheim, H., Grol, R., Faber, M., \& Sibbald, B. (2009). The impact of nonphysician clinicians: Do they improve the quality and cost-effectiveness of health care services?. Medical Care Research $\theta$ Review, 66(6S), 36S-89S. doi:10.1177/1077558709346277

Lowery, B., Scott, E., \& Swanson, M. (2016). Nurse practitioner perceptions of the impact of physician oversight on quality and safety of nurse practitioner practice. Journal of American Association of Nurse Practitioners, 28, 436-445. doi:10.1002/2327-6924.12336

Maier, C. B. (2015). The role of governance in implementing task-shifting to nurses in advanced roles in Europe, U.S., Canada, New Zealand and Australia. Health Policy, 119(12), 1627-1635.

Martinez-Gonzalez, N. A., Tandjung, R., Djalali, S., \& Roseman, T. (2015). The impact of physician-nurse task shifting in primary care on the course of disease: A systematic review. Human Resources for Health, 13 (55), 1-14 doi:10.1186/s12960-015-0049-8

Maylone, M. M., Ranieri, L., Quinn Griffin, M. T., McNulty, R., \& Fitzpatrick, J. J. (2011). Collaboration and autonomy: Perceptions among nurse practitioners. Journal of the American Academy of Nurse Practitioners, 23, 51-57. doi:10.111/j.1745-7599.2010.00576.x

McInnes, S., Peters, K., Bonney, A., \& Halcomb, E. (2015). An integrative review of facilitators and barriers influencing collaboration and teamwork between general practitioners and nurses working in general practice. Journal of Advanced Nursing, 71(9), 1973-1985. doi:10.1111/jan.12647

Mitchell, R., Paliadelis, P., McNeil, K., Parker, V., Giles, M., Higgins, I., ... Ahrens, Y. (2013). Effective interprofessional collaboration in rural contexts: A research protocol. Journal of Advanced Nursing, 69(10), 2317-2326. doi:10.1111/jan.12083

National Council of State Boards of Nursing. (2016). APRN consensus model. Retrieved May 5, 2016, from http://www.ncsbn.org

Newhouse, R. P., Stanik-Hutt, J., White, K. M., Johantgen, M., Bass, E. B. Zangaro, G., ... Weiner, J. P. (2011). Advanced practice nurse outcomes 1990-2008: A systematic review. Nursing Economic, 29(5), 230-250

Pasarón, R. (2012). Nurse practitioner job satisfaction: Looking for successful outcomes. Journal of Clinical Nursing, 22, 2593-2604. doi:10.1111/j.1365$2702.2012 .04331 . x$

Penz, K. L., \& Stewart, N. J. (2008). Differences in autonomy and nursephysician interaction among rural and small urban acute care registered nurses in Canada. Online Journal of Rural Nursing and Health Care, 8(1), 39-53.

Petersen, P. A., Keller, T., Way, S. M., \& Borges, W. J. (2015). Autonomy and empowerment in advanced practice registered nurses: Lessons from New Mexico. Journal of the American Association of Nurse Practitioners, 27(7), 363-370. doi:10.1002/2327-6924.12202

Pulcini, J., Jelic, M., Gul, R., \& Yuen Loke, A. (2010). An international survey on advanced practice nursing education, practice, and regulation. Journal of Nursing Scholarship, 42(1), 31-39. doi:10.1111/j.1547-5069.2009.01322.x

Ricketts, T. C. (2000). The changing nature of rural health care. Annual Review Public Health, 21, 639-657.

Sheer, B., \& Wong, F. K. Y. (2008). The development of advanced nursing practice globally. Journal of Nursing Scholarship, 40(3), 204-211.

Wade, G. H. (1999). Professional nurse autonomy: Concept analysis and application to nursing education. Journal of Advanced Nursing, 30(2), 310-318.

Weiland, S. A. (2008). Reflections on independence in nurse practitioner practice. Journal of the American Academy of Nurse Practitioners, 20(4), 345-352. doi:10.1111/j.1745-7599.2008.00330.x 